Revue d'histoire de l'Amérique française

RAS REVUE D.HISTOIRE DE L'AMÉRIQUE FRANÇAISE

\title{
La criminalité à Québec sous le régime français - étude statistique
}

\section{André Lachance}

Volume 20, numéro 3, décembre 1966

URI : https://id.erudit.org/iderudit/302588ar

DOI : https://doi.org/10.7202/302588ar

Aller au sommaire du numéro

Éditeur(s)

Institut d'histoire de l'Amérique française

ISSN

0035-2357 (imprimé)

1492-1383 (numérique)

Découvrir la revue

Citer cet article

Lachance, A. (1966). La criminalité à Québec sous le régime français — étude statistique. Revue d'histoire de l'Amérique française, 20(3), 409-414.

https://doi.org/10.7202/302588ar d'utilisation que vous pouvez consulter en ligne.

https://apropos.erudit.org/fr/usagers/politique-dutilisation/ 


\title{
LA CRIMINALITE À QUÉBEC SOUS LE REGIME FRANÇAIS * \\ ÉTUDE STATISTIQUE
}

\author{
"Aussi loin qu'on remonte dans \\ l'histoire, le crime apparaît comme \\ l'une des constantes de l'expression \\ passionnelle de l'homme."
}

Naim Kattam.1

Tout crime quel qu'il soit est une offense contre la société ${ }^{2}$, ainsi l'étude du crime à une période précise de l'histoire aidera à mieux connaître la société de cette époque. Voilà le but que nous poursuivons en étudiant la criminalité à Québec sous le régime français.

Les statistiques criminelles de cette étude sont basées sur le nombre de violations de l'Ordonnance criminelle de 1670 rapportées au lieutenant-général "civil et criminel" de la prévôté de Québec et pour lesquelles il y eut poursuite en justice devant les tribunaux de la prévôté de Québec ou du Conseil souverain.

La plupart des crimes que le code pénal actuel décrète comme tel, nous les retrouvons dans l'Ordonnance criminelle de 1670 qui était en vigueur au Canada durant la seconde moitié du XVIIème siècle et la première moitié du XVIIIème siècle. Cette ordonnance avait l'avantage de résumer le droit criminel de l'époque. Nous y relevons les lois criminelles qui avaient d'abord été décrétées dans l'ordonnance de Louis XII du mois de mars 1499 et dans celle de Villiers Cotterets du mois d'août

* Appendice d'un volume, Le bourreau au Canada sous le régime français, qui sera publié, au cours de décembre, par la Société historique de Québec.

1 Naim Kattam, "Le crime et la société américaine" dans Cité Libre, XV, no 77 (juin 1965) : 24.

2 John Barron May, Crime and the Social Structure, 11. 
1531, pour ne nommer que les deux plus importantes. En fait l'Ordonnance criminelle de 1670 constituait un véritable recueil des lois criminelles en vigueur en France et au Canada sous le régime français. Et non seulement nous y retrouvons la plupart des crimes que le code pénal actuel décrète, mais aussi un certain nombre de délits qui, aujourd'hui, sont disparus des codes modernes, tels que l'adultère, l'hérésie, le blasphème, le sortilège, la sorcellerie, etc.... ${ }^{3}$. Ce sont donc tous ces crimes mentionnés dans l'Ordonnance criminelle de 1670 que nous avons recherchés. Nous les avons dénombrés et divisés en quatre grandes catégories: premièrement les délits concernant des "attaques contre la propriété d'autrui", deuxièmement les délits concernant des "attaques contre la personne",4 troisièmement les délits concernant des attaques contre les mœurs et enfin quatrièmement les délits concernant des attaques contre l'État.

\section{I - LES "ATTAQUES CONTRE LA PROPRIÉTÉ D'AUTRUI"}

A Québec, sous le régime français, environ $50 \%$ de tous les délits furent des attaques à la propriété d'autrui. Donc il semble bien que ces délits constituaient le principal problème de criminalité à Québec à cette époque. Et pourtant ce n'était pas parce que les juges n'étaient pas sévères envers les criminels, puisque pour ces attaques à la propriété d'autrui 10 personnes furent condamnées à la pendaison, 23 au fouet, 12 aux galères, 12 au carcan, 11 à la flétrissure, 11 au bannissement et 1 au chevalet.

Dans cette catégorie, nous considérons comme une attaque à la propriété d'autrui tout vol, tout cas de recel, toute affaire de désertion de domestique et enfin tout incendie volontaire. C'est ainsi qu'à Québec, durant tout le régime français, nous avons pu compter 44 attaques contre la propriété d'autrui pour lesquelles 55 personnes, dont 6 femmes, ont été condamnées. Neuf de ces 44 infractions à la propriété d'autrui ont été accomplies avec l'aide d'un ou deux complices.

3 T.-P. Bédard, "Procès criminel à Québec au XVIIe siècle", dans Revue Canadienne, Nouvelle Série, II (1882): 67.

4 Denis Szabo, Criminologie, 322. 
Parmi ces délits contre la propriété d'autrui, il y eut 38 vols répartis comme suit: 22 vols simples, 12 vols de nuit et 7 vols avec effraction dont 3 la nuit. Nous distinguons ici les vols nocturnes des vols simples parce que, sous le régime français, constatant le peu d'éclairage des rues et l'absence de guet, la nuit, ce qui avait pour effet de faciliter le travail de maraudeurs nocturnes et de rendre la sécurité des habitants très fragile, ${ }^{5}$ la Justice était très sévère pour ce genre de délit. Nous avons aussi rencontré 3 cas de recel, 3 affaires de désertion de domestique, 1 cas d'effraction simple sans vol et 1 cas d'incendie volontaire.

Quant à la décennie où on s'attaqua le plus à la propriété d'autrui, ce fut celle entre 1750 et 1759 où nous avons compté 11 délits du genre.

\section{II - les "ATtAQues CONTRE la PERSONNE"}

Contrairement aux crimes de la catégorie précédente, qui pouvaient rationnellement s'expliquer par le fait que les criminels désiraient acquérir par des moyens illégaux des biens que tout être normal peut rêver de posséder un jour, les crimes contre la personne sont souvent inexplicables par la raison et également énormément idiosynerasique. C'est pourquoi l'Homme, ne pouvant expliquer rationnellement cet emploi subit de violence et de force à l'égard d'une autre personne, est portée à s'indigner beaucoup plus d'un tel crime que de tout autre délit. ${ }^{~}$ C'est ainsi que, sous le régime français, les personnes qui s'étaient rendues coupables de délits semblables étaient complètement rejetées de la société et même cette dernière prenait plaisir à assister à leurs exécutions sur la place publique.

Tous les cas de meurtre, d'homicide involontaire, de duel, de suicide, d'infanticide, d'avortement, d'empoisonnement, de rapt, de diffamation et de querelle ont été groupés dans cette catégorie. Dans la capitale de la Nouvelle-France, nous avons compté 23 attaques contre la personne pour lesquelles 32 individus, dont 7 femmes, ont été condamnés. Mentionnons aussi

5 Marcel Trudel, L'esclavage au Canada fraņ̧ais (Presses universitaires Laval, 1960), 216s.

6 Gresham M. Sykes, Crime and Society, 50. 
que 7 de ces 23 délits ont été accomplis avec l'aide d'un ou deux complices. Ces infractions à l'Ordonnance criminelle de 1670 se répartissaient de la façon suivante: 4 meurtres, 4 cas de duel, 4 cas de diffamation, 3 cas de querelle, 2 cas d'avortement, 1 cas de suicide, 1 cas de tentative de suicide, 1 cas d'homicide involontaire, 1 cas d'empoisonnement, 1 cas d'infanticide et 1 cas de rapt. Enfin c'est entre 1750 et 1759 où il y eut le plus d'attaques contre la personne, soit 4.

\section{III - LES ATTAQUES CONTRE LES MCEURS}

Sous ce titre nous avons réuni tous les délits sexuels, tels que viol, adultère, séduction, etc...., et tout ce qui était contraire aux mœurs du Canada sous le régime français, tels que le blasphème, le dévergondage, l'ivresse, etc....

Or les juges de la prévôté de Québec et du Conseil souverain furent assez sévères pour les personnes coupables de délits semblables à cause surtout du scandale public qui en résultait. C'est ainsi que parmi ceux qui commirent des délits sexuels, à Québec, 1 individu fut condamné à être pendu, 2 à être fouettés puis à avoir la tête rasée et à ramer sur les galères du Roi, et 2 autres, dont une femme, à faire amende honorable en public, puis à être fouettés et finalement bannis du pays.

Durant tout le régime français, nous avons compté, à Québec, 10 attaques contre les mœurs pour lesquelles 11 personnes ont été condamnées. Nous y avons dénombré 4 cas d'ivresse, 2 cas de blasphème, 2 cas de viol, 1 cas de séduction, 1 cas d'adultère et 1 cas de dévergondage. Mentionnons en terminant que la décennie où il y eut le plus d'infractions du genre, à Québec, fut celle entre 1640 et 1649 , alors que 5 offenses contre les mœurs furent commises: la majorité de ces délits, cependant, étant des cas d'ivresse.

\section{IV - LES ATTARUES CONTRE L'ETAT}

Dans ce genre d'infractions, le criminel ne s'attaque pas à une personne en particulier, mais plutôt à l'ensemble de la société qui se trouve ainsi lésée par un tel délit. 
Dans cette dernière catégorie, toutes les infractions à des lois ou ordonnances décrétées par le gouvernement colonial ou métropolitain furent groupées. C'est ainsi que nous retrouvons réunis ici les délits concernant le faux-monnayage, la désertion du pays "sans permission", la désobéissance à des ordonnances de l'Etat telles que celle contre les coureurs de bois et celle touchant la traite de l'eau-de-vie aux Indiens.

Dix infractions du genre se produisirent, à Québec, sous le régime français, pour lesquelles 12 hommes furent condamnés. En effet 9 faux-monnayeurs, 1 déserteur, 1 coureur de bois et 1 traiteur d'eau-de-vie furent traduits devant les tribunaux québecois. Enfin ce fut encore la dernière décennie du régime français qui connut le plus de délits du genre, soit 3 .

En terminant, essayons d'avoir une vue d'ensemble sur la criminalité à Québec. Nous constatons d'abord que 87 délits criminels ont été commis à Québec durant tout le régime français, soit 43 infractions au XVIIème siècle et 44 durant la première moitié du XVIIIème siècle. Ces statistiques nous permettent de calculer le taux de criminalité pour le XVIIème siècle, soit 1 crime par 139 habitants environ, et pour le XVIIIème siècle, soit 1 crime par 150 habitants environ, ce qui fait, pour l'ensemble du régime français, un taux moyen de 1 crime par 144.5 habitants. On remarque, à partir de ces données, que le taux de criminalité à Québec est plus élevé au XVIIème siècle et pourtant la décennie où il y eut le plus de délits criminels se trouve au XVIIIème siècle, soit entre 1750 et 1759 . En effet 18 infractions furent commises durant cette dernière période $d u$ régime français. Cette recrudescence des délits criminels peut d'abord s'expliquer par la période troublée que traversa alors la Nouvelle-France, mais la principale explication est que la ville de Québec de plus en plus se peuplait. C'est ainsi qu'en l'espace de dix ans, la population de la capitale de la NouvelleFrance doubla presque, passsant de 4,600 en 1744 à 8,000 habitants en 1754, pour atteindre finalement en 1760 le chiffre de 12,000 âmes ?.

7 Recensements du Canada, 1665 à 1871, IV: 60ss. 
Enfin, en résumé, mentionnons que pour ces 87 délits criminels, 110 personnes, parmi lesquelles il y avait 14 femmes, ont été condamnées dont 55 , soit $50 \%$, pour des infractions à la propriété d'autrui.

Voilà en somme le portrait que l'histoire nous a laissé de la criminalité à Québec sous le régime français.

Collège de Lévis.

ANDRÉ LACHANCE, D.E.S. (histoire).

\section{ARTICLES À PARAITRE}

Nous demandons à nos collaborateurs d'être patients. En mars prochain, paraîtra l'Index des dix premières années de la Revue. Nous gardons précieusement les manuscrits qui nous ont été envoyés. Et nous les ferons paraître aussitôt que possible.

Jean-P. Angrignon, Mutation des temples protestants dans le centre le la ville de Montréal.

Gabriel Debien, La christianisation des esclaves des Antilles françaises, aux XVIIe et XVIIIe siècles.

Sœur Sainte-Thérèse Désilets, Une figure politique du XIXe siècle: sir François-Xavier Lemieux.

Robert Le Blant, Les débuts difficiles de la Cie de la Nouvelle-France: l'affaire Langlois, 1628-1632.

Ulric Lévesque, Les élèves du Collège de Sainte-Anne-de-la-Pocatière, 18291942.

Yves Poutet, Jacques II, MacMahon et Kennedy.

Dom Guy Oury, Un nouveau manuscrit des Lettres de Marie de l'Incarnation.

Konrad Filion, Essai sur l'évolution du mot habitant.

Yves Garon, a.a., Qui était "Pierre-André", le premier critique de notre premier roman?

Robert-Lionel Séguin, L'“apprentissage” de la chirurgie en NouvelleFrance.

Maurice Filion, La crise de la marine française d'après le mémoire de Maurepas de 1745 sur la marine et le commerce.

Gilles Archambault, La question des vivres au Canada au cours de l'hiver 1757-1758.

V. Pelletier, Bio-bliographie de Georges Pelletier.

Abbé François Beaudin, Inventaire des documents de 1760-1835.

Mathieu Girard, La pensée politique de J.-P. Tardivel.

Robert Le Blant, Le contrat de mariage de Jean de Lauson et de Marie Gaudart.

R. Massio, La Bigorre et Saint-Domingue au XVIIIe siècle. 